superiority of No. 1553 over No. 897 was also manifest. Of course, in cattle the 'therapeutic index' is much lower ${ }^{8}$; but a single dose of No. 1553 at the rate of $1 \cdot 5-2 \cdot 0 \mathrm{mgm}$. per kilo of body-weight injected into the tissues or intravenously is usually well borne and appears to be the standard curative dose (Carmichael and Belli1). Neither No. 897 nor No. 1553 protects normal mice for longer than a few days (less than four or five) when a large dose is injected subcutaneously and the animals are afterwards inoculated. Prophylactic action in cattle for two to four weeks has been reported, however (Crawshaw ${ }^{12}$, Stewart ${ }^{13}$.

The occasional occurrence in cattle, some weeks after treatment, of toxic symptoms resembling photosensitization (Bell ${ }^{14}$ ) has been an undesirable complication of therapy with phenanthridine No. 1553. The precise conditions determining the development of those effects have not been defined. Similar phenomena have been recorded apart from treatment, and nothing comparable has been produced in small rodents (Brownlee et al. ${ }^{15}$ ). Where cure fails to occur in cattle, the relapses seem generally to be less amenable to further dosage with phenanthridine drugs. This soon emerged with No. 897 , and has been attributed to the rapid acquisition of drug-resistance by the trypanosomes. But our persistent attempts to produce drug-fast strains in mice by the various known methods have failed; for example, where repeated relapses were on each occasion treated with a single injection of a dose curative for less than 40 per cent of original infections at acme, sterilization was effected ultimately in the same proportion, cure resulting even after the twentieth relapse ${ }^{4,5}$. The diminished therapeutic response in relapsed cattle seems similar to our observations with chronic strains in mice. By analogy, it is possible that drugfastness of the trypanosomes may develop more readily in one species of host than in another. But the problem as regards cattle requires more extensive investigation than it seems to have received so far.

On comparing acme strains derived originally from different natural sources, marked differences were found in virulence, susceptibility to the ehemotherapeutic drug and 'solidity' of immunity to re-inoculation with the homologous strain following cure $^{4,5,8}$. As regards immunity, with one strain animals were refractory to a single massive reinoculation more than a year after cure, or to repeated re-inoculations over this period. This suggests a method of protecting herds by artificial inoculation followed by treatment. On the other hand, with another strain only 50 per cent of animals resisted re-inoculation even after recent cure; and of these again, 50 per cent became infected after a second re-inoculation and so on. Little or no cross-immunity exists between different acme strains. Those differences have persisted without noteworthy change during many years of 'syringe-passage'. It remains to be determined whether in their natural habitat strains from cattle in one locality show considerable uniformity, or whether a variety of strains with distinct characters exist side by side in the same place.

T. vivax infection (in cattle) also responds to the phenanthridine compounds which are effective against $T$. congolense; but no member of the series is very potent toward $T$. brucei. T. cruzi infection in mice (one strain tested) is influenced by certain members ${ }^{16}$, especially 3-carbethoxyamino-9-p-carbethoxyaminophenyl-10-methylphenanthridinium chloride (or methanesulphonate) and also 2:7-dicarbethoxyamino-9 : 10-dimethylphenanthridinium methosulphate, neither of which acts on $T$. congolense or $T$. brucei except in maximal doses.

${ }^{1}$ Morgan, G., and Walls, L. P., with a note by Browning, C. H., Gulbransen, R., and Robb, J. V. N., J. Chem. Soc., 389 (1938) ${ }^{2}$ Browning, C. H., Morgan, G. T., Robb, J. V. M., and Walls, L. P., J. Path. Bact., 46, 203.(1938)'.

${ }^{3}$ Browning, C. H., Browning, P., and Robb, J. V. M., J. Path. Bact., 50, $371(1940)$

4 Browning, C. H., and Calver, K. M., J. Path. Bact., 55, 393 (1943).

'Calver, K. M., Trop. Dis. Bull., 42, 704 (1945) (summary of thesis for degree of Ph.D., University of Glasgow).

${ }^{6}$ Adamson, H. (unpublished).

${ }^{7}$ Walls, L. P., J. Soc. Chem. Indust., 66, 182 (1947) ; J. Chem. Soc., 1031 (1946); ibid., 67 (1947).

${ }^{8}$ Browning, C. H., Calver, K. M., and Adamson, H., J. Path. Bact., 60, 336 (1948).

'Fulton, J. D., and Yorke, W., Ann. Trop. Med. Parasitol., 37, 80 (1943).

${ }^{10}$ Wien, R., Brit. J. Pharm. Chemotherap., 1, 65 (1946).

${ }^{11}$ Carmichael, J., and Bell, F. R., Vet. Rec., 58, 495 (1944)

${ }^{12}$ Crawshaw, H. A., J. Comp. Path. Ther., 57, 13 (1947)

13 Stewart, J. L., J. Comp. Path. Ther, , 57, 79 (1947).

14 Bell, F. R., Vet. Rec., 57, 449 (1945); Ann. Trop. Med. Parasit., 41, $165(1947)$

${ }^{15}$ Brownlee, G., Goodwin, L. G., and Walls, L. P., Vet. Rec., 59, 518, (1947).

${ }^{16}$ Browning, C. H., Calver, K. M., Leckie, M. W., and Walls, L. P., Nature, 15\%, 263 (1946)

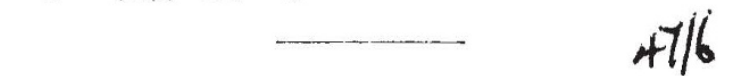

METEOROLOGY IN AGRICULTURE

$7 \mathrm{HE}$ ordinary meeting Mothe Royal Meteorological Society on March I took the form of a discussion of weather polem in farming, three speakers presenting preparod papers. As these papers could not be circulatedin advance, they had to be read in full, so that general dircussion was restricted in time, and would have pepn pven more so if one of the three hadmot been Pls-sacificing by confining himself to a few comments.

Opening the meeting, Dr. H. L. Penman directed attention to three kinds of problem: statistical, biological and physical. Statistical problems include, among others, the forecasting of both weather and crop yields. Of the former, he said that when they could be obtained, long-range forecasts would be of immense value; but even the scope of present-day forecasting technique could be made more useful to farmers, and this point was emphasized in the later discussion by Dr. J. Meiklejohn, who urged the establishment of a regional forecast service designed in language and scope for the particular needs of farmers and not exclusively for the benefit of agricultural scientists. Dr. Penman stated that attempts to forecast crop yields from weather data had a long history of failure, a failure due to neglect of the biological side of the problem; but in spite of his plea that future activity of this kind should start with biological measurements, Prof. Dudley Stamp asked that more meteorological measurements should be taken to help land utilization experts and town planners to do their job less harmfully to farming interests. Another contributor to the discussion, Mr. A. W. Ireland, from the Sudan, pointed out that yields of irrigated cotton can be predicted with considerable certainty merely from a knowledge of rainfall before sowing.

Biological problems, Dr. Penman continued, involve quantitative study of the growth, spread and decay of biological activity and their dependence on weather, and present a wide field for research in general and local meteorology and in micro-meteor- 
ology, in which the objective must be to answer some particular biological question. Some of these problems present a challenge to meteorological physicists on their own ground, for turbulent transport of spores and pollen involves the same ideas as turbulent transport of heat and water vapour, but are at least one degree more difficult because the suspended material has a terminal velocity of settling too big to be neglected in the analysis. Physical problems of importance in farming include not only the analysis of this turbulent diffusion, but also study of the heat balance of the earth-always of importance, but particularly so in investigating early summer radiation frosts-and of the water balance, since water is indispensable in any system of farming.

As an illustration of the application of fundamental physical research to practical farming, Dr. Penman then outlined work recently done at Rothamsted on the relation between weather and water consumption by crops. Because of the large latent heat of vaporization of water, much of the incoming energy from the sun is used up in evaporating water-if the water is there to be evaporated-and by measuring or estimating other components of lesser importance it is possible to draw up an energy balance-sheet in which the only unknown is evaporation. This theoretical work can be employed in practice to estimate the transpiration-rate from a fresh green crop with an adequate water supply, given measurements of wind speed, air temperature, dew-point temperature and duration of bright sunshine. The condition of 'adequate water supply' being the condition aimed at in any good irrigation system, the treatment is directly applicable to irrigation control. To demonstrate this, he described an experiment on irrigation of sugar beet on a Surrey market garden during 1948 in which one of the irrigation treatments was controlled on the basis of data returned weekly from a small weather station set up on the experimental field. In the course of the summer, irrigation was called for three times (total applied, $2 \cdot 6$ in.), but in all cases subsequent rainy periods rendered these irrigations superfluous, or almost so. In addition to unirrigated control plots, a third set was irrigated at the farmer's discretion (five times; total applied $4 \cdot 7$ in.), but because natural rainfall was estimated to have been entirely adequate, no major differences in yield were expected. Nor were they obtained, though there was a slight, non-significant bias in favour of the plots that had restricted irrigation. Soil samplings before and during the cropping confirmed the weather-based estimates of the amount of moisture removed by the crop.

Dr. L. Broadbent then gave a survey of the weather problems encountered by biologists, with particular reference to the potato. His main concern was the intervention of weather in attempts to produce full yields of healthy potatoes; but he commented also on problems of storage in clamps and the degree of thermal and physical insulation that must be provided to prevent too rapid heat loss in cold, moderately calm weather and to prevent penetration of cold air in windy weather. Logically, it can be interpolated here that Mr. R. W. Gloyne also made a brief reference to deterioration of 'seed' potatoes during transit from Scotland to southern England, and the problem of determining night radiation losses of heat from the railway trucks in which the potatoes are carried.

The need for this annual transfer of seed took up the greater part of the remainder of Dr. Broadbent's paper. Because of the weather conditions in the seed-raising areas and the general absence of winter host plants for the insect vector, the seed from Scotland arrives almost, if not completely, free from virus disease. Odd tubers, however, might have such a disease, and potatoes left in the ground from an earlier crop might have it, so that invariably all English potato crops carry a few nuclei of infection. The infection is spread by the aphid, Myzus persicce, and Dr. Broadbent gave an interesting account of his experiments to determine those micro-meteorological conditions within the potato crop that would lead to insect movement from plant to plant, or inhibit it; since the insect carries the disease with it, the study of spread of the disease is, in fact, largely the study of the movement of the insect. He first showed the inadequacy of Stevenson screen temperatures as guides to what is happening inside the crop, and although in the later discussion there were some good-natured sallies against such screen readings, the chairman, Mr. E. Gold, clearly expressed the feeling of the meeting in stating that while for general synoptic surveys the standard screen is adequate, for particular problems data would have to be collected in other ways. To this Mr. W. H. Hogg added the comment that night minima in the screen seem to be reasonably representative of those measured in Dutch lights at ground-level.

Dr. Broadbent also gave an account of work, largely exploratory and still in the pioneering stage, aimed at measuring temperature and humidity gradients, and the degree of air movement, inside potato crops of different spacings and vigour. The aphid will not fly if the air-speed around it is more than 3-4 m.p.h.; but even the early results show conclusively that flying conditions may often be suitable inside the crop when they are unsuitable outside, so that a chance eddy, or an imprudent excursion, may take the insect out into the faster. moving air to be swept uncontrollably along to another part of the same field, to another field, or even to another county-carrying infection with it if it was previously feeding on an infected plant.

It was unfortunate that Mr. R. W. Gloyne, of the newly formed Agricultural Branch of the Meteoro. logical Office, had to compress his remarks, but even so he gave a fascinating glimpse of his activities as meteorological attaché to the south-west province of the National Agricultural Advisory Service in Britain. $\mathrm{He}$, too, was concerned with potatoes, not only with the transit of seed and storage of tubers but also with the possibility of issuing special weather forecasts of the imminence of the hot humid conditions that lead to rapid multiplication of the spores of potato blight, one of the few diseases that has a clearly marked and fairly well-known association with a particular typo of weather. Of special forecasts in general, he, like a later contributor to the discussion, pointed out that farming has to go on whatever the forecast, and that we must be careful not to over-estimate the value of farmers' weather forecasts, particularly for men working on a small scale. For large units, however, such forecasts might realize their expected value.

The scale of farming activity and its dependence on weather appeared also in another of his topics, which he referred to as "farming climatology". Many harvesting operations, of which haymaking is an outstanding example, can only be successfully carried out if there is a certain weather sequence, usually of days without rain, at the time of the operation; the amount of crop that can be successfully harvested is 
limited by the length of this suitable period, by the labour and equipment available for the job, and by the technique used for the operation. For a given size of farm with normal staff and equipment, the optimum area of crop will be limited by the probability of getting the necessary weather sequence and by the harvesting technique. For hay, eastern England can count on a long sequence of good haymaking days, so the technique used there may not be equally successful in the south-west with its higher and more frequent rainfall; the most effective technique for the south-west would be one making some allowance for the climate of the region.

A further general topic led Mr. Gloyne to a point of particular interest. As is well known, dusting and spraying techniques against insect attack and plant pathogens are, like the spreading of some fertilizers, at the mercy of the wind. The wind-speed above which control becomes very difficult varies with particle-size and spreading technique; but it is usually a long way below gale force, and for finer materials may be only a few miles an hour. When the material is suspended or dissolved in water, high-pressure spraying is usually successful; but there are areas so short of water that it must be applied as a dust, and the problem arises of finding some means of making the dust stick to the plants. A heavy dew deposit will serve, and Mr. Gloyne had been asked if it would be possible to get forecasts of occasions on which early mornings of heavy dew would be followed by conditions calm enough for dusting operations to be carried out without undue loss by blowing away.

Mr. Gloyne's final remarks would be broadly accepted by most present : meteorology should be more concerned with growing food and less with getting an aeroplane from place $A$ to place $B$; and an early resumption of the discussion was highly desirable.

H. L. P. $3 \| 6$

\section{NUTRITION AND FERTILITY}

$\mathrm{T}$ HE War accenthated the difficulties of food production and the maintenance of an adequate diet for humandise. Actual destruction and the diversion of humar ctivity to destructive aims, mass mot menter the population to avoid or assist mithy.operatchs, and the natural increase of the poplation, which in spite of these disturbances continued with very little check, have brought peace-time problems of great urgency : how to maintain or raise the standard of nutrition, and at the same time make provision for the increasing population or alternatively how to control the rate of increase. Nutrition and fertility are therefore socially and economically related as well as causally connected. The emphasis of the Conference held by the Nutrition Society on March 5 was on the causal connexions, but many experiences were drawn from the social and economic spheres. Thus, Dr. G. I. M. Swyer directed attention to the apparent paradox that in the East (China, India, etc.) a high birth-rate and expanding population is associated with poverty and under-nourishment, whereas in the West adequate nourishment is associated with a stationary or declining population. Prof. A. St. G. Huggett, on the other hand, instanced the effects of starvation or near starvation on the depression of the conceptual-rate, birth-rate and birthweight, and increase in abortion-rate and prematurity. rate, in the populations of Stalingrad and Holland during the worst periods of the War. Dr. J. Edwards showed that data collected from animal artificial insemination centres primarily concerned with increasing the milk production could be analysed to give valuable information on the effect of seasonal nutrition on bovine fertility. Dr. J. Hammond and Dr. S. J. Folley both drew inferences on the effects of nutrition on fertility from agricultural practice, and Prof. Huggett and Dr. Swyer from clinical medicine.

This approach to the subject from a wide field of generalizations necessarily brought to light the existing lack of exact knowledge on many subjects, which was particularly evident in the case of nutritional therapy. The Conference succeeded, however, not only in directing attention to gaps in our knowledge but also summarized much original and recent research.

Dr. J. Hammond, in his paper on "The Physiology of Reproduction in Relation to Nutrition", gave a very broad review. The onset of puberty is determined by factors outside the gonads; immature ovaries implanted into adult animals function immediately; mature ovaries implanted into immature animals do not function until puberty is reached. The activity of the gonad and body-growth are determined by the hormones of the anterior pituitary, and normally the onset of puberty occurs as the adult growth-rate diminishes, so that the onset of puberty must depend upon a balance of output between the growth hormone and the gonadotrophic hormones. A very high plane of nutrition may reduce the time of onset of puberty, but the weight of the animal at puberty is increased. In the mammal this may be a disadvantage by causing a diversion of nutrients from the embryo and mammary gland to the body tissues. Conversely, poor nutrition leads to delay in the age of puberty, but puberty occurs at a lower body-weight than normal. In this case pregnancy and lactation place a considerable burden on the undergrown mother. Good nutrition increases the number of ova shed. The number of ova fertilized may depend upon the viability of the spermatozoa, and there is some evidence that this is affected by the nutritional condition of the male. Development of the sheep embryo during gestation is affected by the plane of nutrition. The birth-weight and viability of lambs born to ewes underfed during the later stages of pregnancy may be seriously affected and subsequent growth retarded by deficient lactation.

Dr. A. Walton, speaking on "Spermatogenesis and Nutrition", gave an estimate of seminal output in the male and showed how this is related to the total metabolic activity of the testes. The total weekly output of semen even during great sexual activity is extremely small and cannot be regarded as a serious drain on the nutritional requirements. The spermatozoon is a highly differentiated cell in some respects, but genetic argument leads to the conclusion that the nucleus contains half the genes which are common to the somatic cells. The locomotory apparatus and metabolism are similar in most respects to muscle.

Dr. J. Edwards, on "Variations in Fertility Levels in Bovines", analysed data from insemination centres to show that although cows are fed very differently during winter and summer, the conception-rate is not significantly affected. Contrary to common expectation, the lowest rate is found to be in the quarter of the year from April to June. Bulls show no striking effects of nutrition on semen output. Dr. 